\title{
BMJ Open Exploring the patient perspective of fatigue in adults with visual impairment: a qualitative study
}

Wouter Schakel, ${ }^{1}$ Christina Bode, ${ }^{2}$ Hilde P A van der Aa, ${ }^{1}$ Carel T J Hulshof, ${ }^{3}$ Judith E Bosmans, ${ }^{4}$ Gerardus H M B van Rens, ${ }^{1,5}$ Ruth M A van Nispen ${ }^{1}$

To cite: Schakel W, Bode C, van $\operatorname{der}$ Aa HPA, et al. Exploring the patient perspective of fatigue in adults with visual impairment: a qualitative study. BMJ Open 2017;7:e015023. doi:10.1136/ bmjopen-2016-015023

- Prepublication history and additional material are available. To view these files, please visit the journal online (http://dx.doi org/10.1136/bmjopen-2016015023).

Received 10 November 2016 Revised 24 May 2017 Accepted 5 June 2017

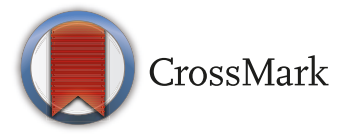

${ }^{1}$ Department of Ophthalmology, VU University Medical Centre and Amsterdam Public Health Research Institute, Amsterdam, The Netherlands

${ }^{2}$ Department of Psychology, Health \& Technology, University of Twente, Enschede, The Netherlands

${ }^{3}$ Coronel Institute of

Occupational Health, Academic Medical Center, University of Amsterdam, Amsterdam, The Netherlands

${ }^{4}$ Department of Health Sciences and Amsterdam Public Health Research Institute, Faculty of Earth and Life Sciences, VU University Amsterdam, Amsterdam, The Netherlands

${ }^{5}$ Department of Ophthalmology, Elkerliek Hospital, Helmond, The Netherlands

Correspondence to

Wouter Schakel;

w.schakel@vumc.nl

\section{ABSTRACT}

Objectives Fatigue is an often mentioned symptom by patients with irreversible visual impairment. This study explored the patient perspective of fatigue in visually impaired adults with a focus on symptoms of fatigue, causes, consequences and coping strategies.

Setting Two large Dutch low vision multidisciplinary rehabilitation organisations.

Participants 16 visually impaired adults with severe symptoms of fatigue selected by purposive sampling. Methods A qualitative study involving semistructured interviews. A total of four first-level codes were top-down predetermined in correspondence with the topics of the research question. Verbatim transcribed interviews were analysed with a combination of a deductive and inductive approach using open and axial coding.

Results Participants often described the symptoms of fatigue as a mental, daily and physical experience. The most often mentioned causes of fatigue were a high cognitive load, the intensity and amount of activities, the high effort necessary to establish visual perception, difficulty with light intensity and negative cognitions.

Fatigue had the greatest impact on the ability to carry out social roles and participation, emotional functioning and cognitive functioning. The most common coping strategies were relaxation, external support, socialising and physical exercise and the acceptance of fatigue.

Conclusions Our results indicate that low visionrelated fatigue is mainly caused by population specific determinants that seem different from the fatigue experience described in studies with other patient populations. Fatigue may be central to the way patients react, adapt and compensate to the consequences of vision loss. These findings indicate a need for future research aimed at interventions specifically tailored to the unique aspects of fatigue related to vision loss.

\section{INTRODUCTION}

Fatigue is an often mentioned complaint by patients with irreversible visual impairment. In fact, they have prioritised fatigue in the top five of problems with the highest rehabilitation urgency. ${ }^{1}$ However, low-vision professionals are at a loss on how to deal effectively with fatigue because currently, no evidence-based treatment options are

\section{Strengths and limitations of this study}

- This qualitative study provides an in-depth exploration of the patient perspective of fatigue in visually impaired adults regarding symptoms of fatigue, causes, consequences and coping strategies.

- Participants were selected from two Dutch low vision multidisciplinary rehabilitation centres through purposive sampling to reflect a range of demographic characteristics (gender, age and work status) and disease characteristics (ophthalmic diagnosis, visual acuity, visual field and disease duration).

- Participant's symptoms of self-reported fatigue were checked with a well-validated instrument to assess fatigue severity.

- A random selection of $10 \%$ of the citations was matched to the existing coding scheme independently by a second researcher to improve reliability of the coding process.

- Limitations include the relatively small sample size and the relatively young age and high amount of rare eye conditions in our sample which may limit the transferability of the findings to the total population of visually impaired adults.

available for the visually impaired population. Cognitive behavioural therapy has proven to be an effective treatment option for fatigue in patients with cancer, ${ }^{2}$ chronic fatigue syndrome $^{3}$ and $Q$ fever fatigue syndrome ${ }^{4}$ but has not been evaluated in patients with visual impairment. To the best of our knowledge, there seem to be no studies available which address the prevalence or determinants of fatigue in visually impaired persons. Previous research on fatigue in visually impaired patients is often limited to patient populations in which fatigue or feelings of exhaustion is a known symptom. ${ }^{5-7}$ In only a few studies, the relation between fatigue and visual impairment has been assessed. MojonAzzi et al found that a greater impairment of vision was associated with a higher probability 
of feeling fatigued. ${ }^{8}$ Similar results have been reported in The Blue Mountains Eye Study by Chia et al. In their population-based study, irreversible visual impairment (due to various eye conditions) was associated with increased fatigue when compared with participants without visual impairment and correctable visual impairment. ${ }^{9}$

Symptoms of fatigue have been found to have a negative impact on psychological well-being, quality of life, employment and work-related activities among patients with chronic disease. ${ }^{10-16}$ Similar results have been reported with respect to the consequences of fatigue in patients with vision loss. In the study of Bruijning et al, ${ }^{17}$ consequences of fatigue mentioned by visually impaired patients included difficulty maintaining energy to endure daily activities (eg, running errands, cooking and work), difficulty concentrating and processing or memorising information, crossing one's personal boundaries regarding energy balance and requiring extra effort to perceive and process visual stimuli. ${ }^{17}$

Studies have shown that fatigue is related specifically to underlying disease mechanisms in different patient populations. ${ }^{13} 1819$ Fatigue in visual impairment might be related to the difficulty of processing visual stimuli which may require more concentration and may result in eye strain. An association between fatigue-related and sleep-related problems has been mentioned in visually impaired patients with some remaining vision ${ }^{20-22}$ and in blind patients because of the disturbance in circadian rhythms. ${ }^{23}$ The positive effect of physical activity on reduction of fatigue ${ }^{24}$ may be difficult to achieve in visually impaired adults because they engage in less physical activity compared with persons without vision loss. ${ }^{25}$ Moreover, fatigue can be a symptom of depression, ${ }^{26}$ a psychological (sub)clinical disorder which is highly prevalent in persons with visual impairment. ${ }^{27}$ Therefore, fatigue may also be related to psychological factors.

To our knowledge, coping strategies to deal with fatigue have not yet been studied in visually impaired adults. In rheumatoid arthritis, it was shown that patients managed fatigue alone without support from healthcare professionals by pacing and rest, relaxation and accepting fatigue as part of the disease. ${ }^{28}$ Rest and sleep were also described to relieve fatigue for patients with ankylosing spondylitis, fibromyalgia, stroke and multiple sclerosis. ${ }^{29}$ In addition, these patients tried to avoid stress and adjusted their activity levels to fit with their reduced capacity. ${ }^{29}$

Given the high rehabilitation urgency of fatigue in low vision ${ }^{1}$ and the expected increase in the prevalence of people with visual impairment due to an ageing society, ${ }^{30}$ further research is crucial to better understand the aetiology of fatigue in this population to develop new treatments. In this context, it is important to understand the concept of fatigue as experienced by the patient because of its subjective and multifactorial nature. According to Leventhal's theory of self-regulation, patients have beliefs and cognitive representations about their illness through illness perceptions. ${ }^{31}$ These representations are an important determinant of behaviour and can have an impact on the way patients cope with their illness. ${ }^{32}$ Understanding these cognitive representations can give insights into the emotional responses to illness which could influence the perceived severity or consequences of fatigue in people with low vision. Qualitative research methods allow an in-depth exploration of subjective symptoms such as the experience of fatigue. The aim of this qualitative study is, therefore, to explore the patient perspective of perceived symptoms, causes, consequences and coping strategies to deal with fatigue in a sample of Dutch patients with visual impairment ( $\geq 18$ years).

\section{METHODS}

\section{Design and participants}

Patients aged 18 years or older registered at two large Dutch low vision rehabilitation organisations were invited to participate in this study. Patients can be referred to these centres based on criteria described in the Dutch guideline 'Vision disorders, rehabilitation and referral' ${ }^{33}$ that mainly follow the WHO criteria, where low vision is defined as the best-corrected visual acuity in the better eye of $<0.3$, but $\geq 0.05$ (Snellen notation) and/or visual field of $<20^{\circ}$ around the central fixation point, or other severe visual field defects. Blindness is defined as the best-corrected visual acuity in the better eye of $<0.05$ and/ or a visual field of $<10^{\circ}$ around the central fixation point. Selection criteria for the study were: (1) sufficient mastery of the Dutch language and (2) having severe symptoms of fatigue as assessed by professionals of the centres (based on their observations of the patient and patient's self-reported fatigue). By purposive sampling, participants were selected to reflect a mix of ophthalmic diagnosis, disease duration, sex, age and working status. Interested patients received an information letter about the study and were informed by telephone by the executive researcher. Our primary interest was fatigue related to visual impairment; therefore, we excluded patients who were treated in the past year for comorbid conditions known for fatigue symptomatology: (1) cancer; (2) multiple sclerosis; (3) chronic fatigue syndrome and (4) psychiatric disorders. Treatment of psychiatric comorbidity, as defined by the Diagnostic and Statistical Manual of Mental Disorders, Fifth Edition, ${ }^{26}$ was screened with the following question: "Are you currently being treated for a psychiatric disorder, or did you receive treatment for a psychiatric disorder in the past year?".

The interviews were conducted at the patients' homes by the first author (WS, psychologist), taking about $90 \mathrm{~min}$. We developed and adapted an interview scheme for our patient population (see online supplementary appendix 1) based on a qualitative study about fatigue in rheumatoid arthritis. ${ }^{34}$ The interview was semistructured in a hierarchical way and consisted of an introduction, open-ended questions and prompts to encourage further discussion or more detailed responses. 


\section{Measurements}

Sociodemographic data and ophthalmic data were collected during the interview. Fatigue severity and vision-related fatigue problems were assessed with the Fatigue Assessment Scale (FAS) ${ }^{35}$ and the 'feeling-fit' scale of the Dutch ICF Activity Inventory ${ }^{36}$ to adequately describe the sample and as a validity check (ie, to check whether participants indeed had severe symptoms of fatigue according to quantitative measures). In addition, symptoms of depression were screened with the Patient Health Questionnaire (PHQ-9) ${ }^{37}$ because of the strong association between fatigue and depression. ${ }^{13}$

\section{Analyses}

All interviews were recorded by a digital voice recorder and transcribed verbatim using F4 software. ${ }^{38}$ For one participant, a descriptive report of the interview was used for analysis due to loss of the recorded audio file. The qualitative data were analysed using Atlas.Ti V.7.5 software. We used an approach similar to the 'framework method' which combines deductive and inductive forms of analysis and is most commonly used for the thematic analysis of semistructured interview transcripts. ${ }^{39} \mathrm{~A}$ total of four first-level codes were top-down predetermined and in correspondence with the research questions (table 2). No additional first-level codes were created after a careful examination of all the interviews. After reading all the phrases of four interviews, second-level codes were created using a bottom-up approach through open coding. Categories were created by axial coding followed by a consensus-based evaluation of these codes in discussion with a second researcher. ${ }^{40}$ Subsequently, the adjusted coding rules and categories were applied to the remaining interviews. New codes could be added to the coding structure during the coding process, but additions were minimal. Hence, it was concluded that saturation had been reached, a point at which no new concepts emerged from new interviews. ${ }^{41}$ A second researcher independently matched $10 \%$ of the citations to the existing coding scheme to estimate inter-rater reliability. Percentage agreement was found for $84 \%$ of the categorisations, $16 \%$ was solved by discussion.

\section{RESULTS}

\section{Sample}

A total of 21 patients were interested to participate in the study of whom 17 participated. Three patients could not be reached after multiple attempts, one person refrained from participation because of personal problems. Data of one participant were excluded from analyses because he was being treated for a psychiatric disorder in the past year, resulting in data of 16 patients. At this point, no further interviews were conducted because of data saturation. The characteristics of the 16 participants are shown in table 1.

The majority of participants were male, lived together with a partner and had no comorbidity. The average age
Table 1 Demographic characteristics of the study population $(n=16)$

\begin{tabular}{|c|c|c|c|}
\hline & $\mathbf{n}$ & $\%$ & Range \\
\hline \multicolumn{4}{|l|}{ Gender } \\
\hline Female & 7 & 44 & \\
\hline Male & 9 & 56 & \\
\hline Age in years (mean $\pm S D$ ) & $51 \pm 13$ & & $30-77$ \\
\hline \multicolumn{4}{|l|}{ Work status } \\
\hline Occupational disability & 6 & 38 & \\
\hline Voluntary work & 5 & 31 & \\
\hline Employed & 4 & 25 & \\
\hline Retired & 1 & 6 & \\
\hline Marital status, living together & 11 & 69 & \\
\hline \multicolumn{4}{|l|}{ Primary cause of visual impairment } \\
\hline Retinitis pigmentosa & 4 & 25 & \\
\hline Glaucoma & 2 & 13 & \\
\hline Ablatio retinae & 2 & 13 & \\
\hline Neurosarcoidosis & 1 & 6 & \\
\hline Congenital cataract & 1 & 6 & \\
\hline Usher syndrome & 1 & 6 & \\
\hline Ocular albinism & 1 & 6 & \\
\hline Retinoblastoma & 1 & 6 & \\
\hline Leber congenital amaurosis & 1 & 6 & \\
\hline Choroideremia & 1 & 6 & \\
\hline Diabetic retinopathy & 1 & 6 & \\
\hline $\begin{array}{l}\text { Time since diagnosis in years } \\
\text { (mean } \pm \text { SD) }\end{array}$ & $18 \pm 15$ & & $1-49$ \\
\hline Comorbid diseases & & & $0-4$ \\
\hline 0 & 10 & 63 & \\
\hline$\geq 1$ & 6 & 37 & \\
\hline \multicolumn{4}{|l|}{ Fatigue severity } \\
\hline FAS (mean \pm SD) & $29 \pm 7$ & & $16-46$ \\
\hline Fatigued (FAS $\geq 22)$ & 14 & 88 & \\
\hline $\begin{array}{l}\text { Vision-related fatigue (mean } \pm \\
\text { SD) }\end{array}$ & $15 \pm 5$ & & $9-28$ \\
\hline \multicolumn{4}{|l|}{ Depressive symptoms } \\
\hline PHQ-9 (mean \pm SD) & $8 \pm 4$ & & $3-17$ \\
\hline $\begin{array}{l}\text { Moderate/severe symptoms } \\
(\mathrm{PHQ}-9 \geq 10)\end{array}$ & 6 & 38 & \\
\hline
\end{tabular}

FAS, Fatigue Assessment scale; PHQ-9: Patient Health Questionnaire.

of the participants reflected a middle-aged sample, but only a minority was still employed. Vision loss was caused by relatively rare eye diseases, with retinitis pigmentosa as the most frequently reported primary diagnosis. Cataract was present in two participants in addition to their primary cause of visual impairment. The FAS questionnaire showed a fatigue prevalence of $88 \%$ (FAS $\geq 22$ ), indicating that the inclusion criterion of self-reported 


\begin{tabular}{|c|c|c|}
\hline First level code & Common categories & $\mathbf{n}^{*}$ \\
\hline \multirow{5}{*}{$\begin{array}{l}\text { Experienced } \\
\text { symptoms of } \\
\text { fatigue }\end{array}$} & Mental & 13 \\
\hline & Everyday symptom & 11 \\
\hline & Physical & 9 \\
\hline & Uncontrollable and unpredictable & 6 \\
\hline & Need to sleep & 5 \\
\hline \multirow{7}{*}{$\begin{array}{l}\text { Perceived causes } \\
\text { of fatigue }\end{array}$} & High cognitive load & 15 \\
\hline & Activities; amount and intensity & 13 \\
\hline & Effort for visual perception & 11 \\
\hline & Difficulty with light intensity & 10 \\
\hline & Negative cognitions & 8 \\
\hline & Comorbidity & 6 \\
\hline & Mobility & 5 \\
\hline \multirow{6}{*}{$\begin{array}{l}\text { Perceived } \\
\text { consequences of } \\
\text { fatigue }\end{array}$} & Emotional functioning & 15 \\
\hline & Social roles and participation & 15 \\
\hline & Cognitive functioning & 14 \\
\hline & Daily activities & 8 \\
\hline & Leisure activities & 4 \\
\hline & Visual functioning & 2 \\
\hline \multirow{6}{*}{$\begin{array}{l}\text { Coping strategies } \\
\text { with fatigue }\end{array}$} & Relaxation & 13 \\
\hline & External support & 12 \\
\hline & Socialising and physical exercise & 11 \\
\hline & Acceptance of fatigue & 10 \\
\hline & Limiting visual perception & 7 \\
\hline & Balancing activities and relaxation & 7 \\
\hline
\end{tabular}

*Number of participants to describe each common category.

fatigue was reflected by the FAS for almost the entire sample. A relatively large proportion of patients (38\%) had moderate to (moderately) severe symptoms of depression (PHQ-9 $\geq 10)$.

\section{Qualitative findings}

First-level codes and common categories of the experience of fatigue related to visual impairment can be found in table 2. Supporting citations for the larger common categories $(n \geq 10)$ are provided in the paragraphs below.

\section{Experienced symptoms of fatigue}

The majority of the participants described fatigue as both a 'mental and physical experience', with feelings of heaviness, languidness and inertia.

You get a little cranky when you're tired, a little apathetic and all, but I feel it in my eyes, and yes, sometimes also in my body. It's just everywhere. (Female, 41, ocular albinism)

Only a few participants reported solely 'physical' or 'mental' elements of fatigue.

The feeling that you don't have muscles anymore, that it's just pudding, just super weak. (Male, 55, glaucoma)
Fatigue is an intense feeling with a heary sensation in my head. As if I'm no longer able to cope with anything. (Male, 30, congenital cataract)

Symptoms of fatigue were reported to be 'present on a daily basis' by more than half of the participants. Several participants also described fatigue as an 'uncontrollable and unpredictable' experience. Almost a third of the participants described their fatigue as 'a need to sleep'. A great variability existed with regard to fatigue expectations, patterns, frequency and severity.

\section{Perceived causes of fatigue}

Almost all participants considered 'a high cognitive load' as a result of their visual impairment the cause of their fatigue. A variety of cognitive processes that require more energy or resources due to the loss of vision were reported, such as memorising information, processing (auditory) information, paying attention to the environment and orientation in the surrounding environment.

You're getting fatigued because you're in a constant state of processing stimuli, that's pretty exhausting. It's really difficult to filter out the right kind of information, sometimes everything is crowding in on you. (Female, 58, Leber congenital amaurosis)

For the majority of the participants, fatigue depended on the 'amount and intensity of actions and activities'.

Well, performing a daily activity that doesn't go as smoothly as you want, because you aren't able to see, really makes you tired. (Male, 49, choroideremia)

More than half of the participants with some remaining vision related the cause of their fatigue to the 'high effort to establish visual perception'. For these participants, more energy is required for focus and accommodation of the eye to perceive visual stimuli.

So your eye is constantly trying to focus, trying to get a sharp image which cannot be obtained. That's really tiresome, it's like a camera making the zzzzzzzz noise when it can't find a point of focus. (Female, 41, ocular albinism)

The 'intensity of light' was also considered as a contributing cause to their fatigue by more than half of the participants. The majority of these participants experienced severe symptoms of fatigue in the absence of light (eg, at dusk), as opposed to some participants who felt more fatigued when exposed to too much light.

For me it's also exhausting whenever it gets dark. It's as if you end up in an introverted state which requires more energy to snap out of. (Female, 54, diabetic retinopathy)

Fatigue was related to negative cognitions for half of the participants. Descriptions included negative thoughts about vision loss and the opinions of others, crossing boundaries in energy levels because of upward comparisons, feelings of inferiority and thoughts and expectations about developing fatigue. 
What also comes into play for me are my negative thoughts about my visual impairment. Like what would other people think whenever I'm walking around with my white cane? Those thoughts take an awful lot of energy as well. (Male, 30, congenital cataract)

Some participants mentioned 'mobility' (eg, travelling, public transport) and 'comorbidity' as a possible cause of their fatigue.

\section{Experienced consequences of fatigue}

Almost all participants reported that fatigue had consequences on 'emotional functioning'; they mentioned frustration, irritability, negative mood and personality changes.

Well, I become gloomy whenever I'm really tired and I start overestimating my own responsibilities, even though they aren't my own responsibilities at all sometimes. (Female, 54, diabetic retinopathy)

In addition, some participants mentioned that fatigue diminishes their emotion regulating capacities.

The fact is, however, that you have less reserves when you're tired, reserves for coping with certain emotions at that moment. (Female, 44, retinitis pigmentosa)

Negative consequences of fatigue on 'social roles and participation' was reported by almost all participants as well; it limits social activities and work and causes patients to feel excluded from society.

Because of my fatigue I'm no longer able to participate in society. (Female, 38, Usher syndrome)

The majority of the participants described a major influence of fatigue on 'cognitive functioning', particularly on concentration, attention and memory.

I find it extremely difficult to really focus on what another is saying in a company, I just let it slide when I'm tired.

(Female, 77, retinitis pigmentosa)

Half of the participants described the consequences of fatigue on 'daily activities', such as household chores, cooking and administration. Some participants mentioned 'withdrawing from leisure activities' as a consequence of fatigue. Only a few participants reported reduced vision when experiencing fatigue.

Coping strategies with fatigue

Almost all participants mentioned 'relaxation' as a coping strategy to reduce fatigue. A variation of relaxation activities were reported, such as napping, listening to music, taking short breaks or going to bed early.

I take a nap almost every day. Well napping, you just want to rest, to close your eyes for a while. (Male, 42, glaucoma)

The majority of the participants reached out for 'external support' of family and friends and professional advice from low vision rehabilitation centres.
I've been to the rehabilitation centre for a couple of years at some time in the past, and this certainly contributed to the process of accepting my fatigue. (Female, 58, Leber congenital amaurosis)

More than half of the participants described the positive effect of 'socialising and physical exercise'. Even though these kind of activities require energy, participants prioritise the positive feeling of achievement over fatigue.

Some activities require tons of energy, sports for example, or going with mates to the pub or a birthday party. But seeing my friends and family is way more valuable than the feeling of being tired. The fact I have to take it easy for a couple of days afterwards is something you're happy to give in to. (Male, 39, retinitis pigmentosa)

Some participants also mentioned gaining energy by being active and participating in social activities.

I like to be physically active. I just like to go for a walk or go cycling, I also really enjoy drinking a beer with my friends, it gives me energy. (Female, 38, Usher syndrome)

More than half of the participants indicated they had accepted their fatigue.

Fatigue is just there, and at some point there is a lot of acceptance. You also adjust your life accordingly to it, you could view fatigue as an enemy but you can also choose to deal with it. That would make it more difficult because fighting against it won't help me anyway. (Female, 58, Leber congenital amaurosis)

Less than half of the participants also described 'limiting visual perception' as a successful coping strategy to deal with fatigue, by using visual aids (eg, filter glasses, braille display, text to speech conversion), performing activities with closed eyes and limiting exposure to light. The same amount of the participants tried to 'create a balance in activities and relaxation' to cope with fatigue.

\section{DISCUSSION}

In this qualitative study, the patient's perspective of fatigue was explored in visually impaired adults regarding symptoms of fatigue, causes, consequences and coping strategies. Fatigue is described as a mental, but also as a physical daily experience, that has consequences for social roles and participation, relationships and emotional and cognitive functioning. The most frequently reported coping strategies for fatigue are relaxation, seeking external support, socialising, physical activities and acceptance.

Compared with the experience of fatigue described in studies with other patient populations, our results show specific causes of fatigue that are related to vision loss. The most often reported cause of fatigue in our sample was high cognitive load; a finding similar to fatigue in hearing loss ${ }^{42}$ but not reported before in other patient populations. ${ }^{12} 284445$ Therefore, a high cognitive load 
may be a specific cause of fatigue for sensory impairments. Compensation for vision loss may result in a high cognitive load due to the necessary adjustments required to maintain daily functioning. In these patients' experiences, processes or activities that are automatic or habitual, now require preparation, mental planning and attention. Patients also describe that they process information in a different way: the loss of visual information is compensated by visual imagery, auditory perception and the constant process of memorising information. This suggests that adaptation to vision loss can be an indirect cause of fatigue because practical solutions such as textto-speech devices are highly demanding for other sensory modalities. Patients and low vision professionals should be aware of this, because fatigue can be a side-effect of rehabilitation interventions to optimise participation. Thus, low vision rehabilitation professionals should make sure that new practical interventions do not exceed the available energy capacity of the patient. Enforcing boundaries and adjusting pacing strategies may be key factors in this process.

The effort required for visual perception was another population-specific cause of fatigue commonly mentioned by respondents in this study. Patients described visual demanding tasks such as reading or display work are tiresome in particular. Possible explanations for this might be that persons with low vision require more energy necessary for focus, strain and accommodation of the eye to establish visual perception. These findings suggest that practical interventions limiting visual perception would be likely to reduce symptoms of fatigue among individuals with low vision. This is in line with our results regarding coping strategies, where some participants described the beneficial effect of performing activities with closed eyes. In addition, our study produced new insights in the association between fatigue and light sensitivity; a study among patients with stroke briefly mentioned this aspect before. ${ }^{29}$ Ameliorating lighting conditions for people with vision loss improves activities of daily living and quality of life $^{46}$ and may also decrease symptoms of fatigue.

Our results show that negative cognitions also play a role in fatigue in visually impaired adults. Participants described a loss of energy because of negative thoughts about their impairment and the opinions of others. For example, some felt misunderstood or disregarded their energy levels because they wanted to function on the same level as their normally sighted peers. These negative cognitions may also be related to the relatively high proportion of depressive symptoms in our sample. This is in line with previous research ${ }^{2747}$ and may be explained by the strong association between vision-specific distress and depression. ${ }^{48}$ Therefore, depressive mood in some participants may also partially explain fatigue, because fatigue is an often coexisting symptom in depression. Interestingly, the majority of the respondents also mentioned negative emotions as a consequence of fatigue. This is in line with the fact that some participants struggled with distinguishing causes from consequences of fatigue.
A possible explanation for this may be that fatigue is circular in nature, in which consequences of fatigue may lead to negative emotions, which in turn could perpetuate fatigue. Cognitive behavioural therapy has proven to be beneficial for fatigue in some patient populations with chronic disease. ${ }^{2}{ }^{3}$ The effect of cognitive behavioural therapy on reducing fatigue has not yet been evaluated in patients with visual impairment but could be promising considering the established evidence for the treatment of depression. ${ }^{49}$ Such a programme could be optimised for persons with visual impairment by focusing on the vision-specific aspects of fatigue.

Consistent with a previous qualitative study in patients with low vision ${ }^{17}$ and qualitative studies in other patient populations, ${ }^{29}{ }^{50}$ we found that fatigue has a negative impact on emotional functioning, the ability to carry out roles, societal participation, cognition and daily activities. It is also noteworthy that patients seemed quite capable of accurately describing their different coping strategies to deal with fatigue. Relaxation, external support, socialising, physical exercise and acceptance of fatigue were identified as important coping strategies. They seemed well educated and actively used rehabilitation services and their own resources to move forward in their coping process with fatigue. However, until now these coping strategies do not seem to be sufficient because fatigue still remains a problem for these patients. Future research is needed to evaluate the effect of fatigue interventions in the visually impaired population. For example, physical exercise therapy, such as aerobic walking or cycling, has been proven to be successful in reducing fatigue and improving well-being for patients with cancer, ${ }^{51}$ multiple sclerosis $^{52}$ and chronic fatigue syndrome. ${ }^{53}$

\section{Strengths and limitations}

Some strengths of the study are the use of a well-validated instrument to assess fatigue severity, which indicated that almost all participants in our sample can be categorised as severely fatigued. Furthermore, our sample consisted of a heterogeneous group with a great variation in gender, work status, visual acuity, visual field and disease duration. Percentage agreement was $84 \%$ for the matching of $10 \%$ of the citations to the existing coding scheme independently by another researcher.

There are some limitations that should be mentioned. First of all, the study consisted of a relatively small sample size. However, these sample sizes are common in qualitative studies, and information saturation was reached. Second, participants from the present study were not examined for biological causes that could explain fatigue, for example anaemia. Last, our sample was relatively young and had relatively rare eye conditions if it were compared with a general population of visually impaired people. This could influence generalisability of the results, especially to older patients who are often faced with age-related causes of vision loss such as macular degeneration. However, the various eye diseases which were the causes of vision loss in the current sample did 
not seem to influence the experience of fatigue. In future research, the possible relation between various eye conditions and fatigue could be examined in more detail by quantitative methods.

\section{CONCLUSION}

Our study showed that fatigue was mainly caused by specific factors related to vision loss according to patients with low vision and fatigue. Evaluation of the literature on the fatigue experience in other chronic illnesses demonstrated similar symptoms, consequences and coping strategies but different perceived causes. The population-specific determinants of fatigue in our study were a high cognitive load, the effort necessary for visual perception, difficulty with light intensity and negative cognitions. Fatigue may be an indirect result of compensation for vision loss because even in light of practical adjustments that are often made in daily life, they often do not fully compensate vision loss and many activities may still require a high cognitive investment. In addition, fatigue may be a result of negative cognitions due to a maladaptive reaction to vision loss or depressed mood. These findings indicate that fatigue in visually impaired adults may not be a direct result of underlying disease mechanisms, but central to the way patients react and adapt to the consequences of vision loss. Future research is warranted because evidence-based interventions to deal with fatigue have not been evaluated for people with visual impairment, and patient's coping strategies appear to be insufficient to effectively deal with fatigue. Low vision professionals and patients should be aware that necessary activities for optimising participation can also have a negative impact on fatigue.

Acknowledgements The authors thank all the participants who agreed to be interviewed for this study and shared their experiences. They would also like to thank the professionals from the low-vision rehabilitation organisations Royal Dutch Visio and Bartiméus for their help with identifying potential participants and recruitment, and Fabian Herdes and Julia Rickers for transcribing some of the interviews.

Contributors The executive researcher (WS), project advisors (CB, HPAvA, CTJH and JEB), project leader (GHMBvR) and principal investigator (RMAvN) conceived the study and its design. WS, CB and RMAvN adapted and developed the interview scheme based on a qualitative study about the patient perspective on fatigue in patients with rheumatoid arthritis. Data collection, analysis and interpretation was performed by WS, with support from CB and RMAvN. WS drafted the manuscript, which was revised by the other authors (CB, HPAvdA, CTJH, JEB, GHMBvR and RMAvN). All authors read and approved the final manuscript. GHMBvR is the guarantor.

Funding The findings of the qualitative study presented here are part of a larger research project on fatigue among visually impaired adults. Financial support for this research project was provided by 'ZonMw InZicht', the Netherlands Organisation for Health Research and Development-InSight Society (Grant Number 60-0063598146), The Hague, The Netherlands.

Competing interests None declared.

Patient consent Detail has been removed from this case description/these case descriptions to ensure anonymity. The editors and reviewers have seen the detailed information available and are satisfied that the information backs up the case the authors are making.
Ethics approval This study was approved by the Medical Ethics Committee of the VU University Medical Centre (Amsterdam, the Netherlands) and has been performed in accordance with the ethical standards laid down in the 1964 Declaration of Helsinki and its later amendments. All patients gave written consent to participate in the present study.

Provenance and peer review Not commissioned; externally peer reviewed.

Data sharing statement No additional data are available.

Open Access This is an Open Access article distributed in accordance with the Creative Commons Attribution Non Commercial (CC BY-NC 4.0) license, which permits others to distribute, remix, adapt, build upon this work non-commercially, and license their derivative works on different terms, provided the original work is properly cited and the use is non-commercial. See: http://creativecommons.org/ licenses/by-nc/4.0/

(c) Article author(s) (or their employer(s) unless otherwise stated in the text of the article) 2017. All rights reserved. No commercial use is permitted unless otherwise expressly granted.

\section{REFERENCES}

1. Bruijning JE. Development of the Dutch ICF Activity Inventory: investigating and evaluating rehabilitation needs of visually impaired adults. 2013.

2. Goedendorp MM, Gielissen MF, Verhagen CA, et al. Psychosocial interventions for reducing fatigue during cancer treatment in adults. Cochrane Database Syst Rev 2009;1:CD006953.

3. Price JR, Mitchell E, Tidy E, et al. Cognitive behaviour therapy for chronic fatigue syndrome in adults. Cochrane Database Syst Rev 2008;3:CD001027.

4. Keijmel SP, Delsing CE, Bleijenberg G, et al. Effectiveness of long-term doxycycline treatment and cognitive-behavioral therapy on fatigue severity in patients with $Q$ fever fatigue syndrome (Qure Study): a randomized controlled trial. Clin Infect Dis 2017;64:998-1005.

5. Farid M, Roch-Levecq AC, Levi L, et al. Psychological disturbance in graves ophthalmopathy. Arch Ophthalmol 2005;123:491-6.

6. Sand KM, Wilhelmsen G, Naess $\mathrm{H}$, et al. Vision problems in ischaemic stroke patients: effects on life quality and disability. Eur $J$ Neurol 2016;23:1-7.

7. Chahin S, Miller D, Sakai RE, et al. Relation of quantitative visual and neurologic outcomes to fatigue in multiple sclerosis. Mult Scler Relat Disord 2015;4:304-10.

8. Mojon-Azzi SM, Sousa-Poza A, Mojon DS. Impact of low vision on well-being in 10 European countries. Ophthalmologica 2008;222:205-12.

9. Chia EM, Wang JJ, Rochtchina E, et al. Impact of bilateral visual impairment on health-related quality of life: the Blue Mountains Eye Study. Invest Ophthalmol Vis Sci 2004;45:71-6.

10. Wolfe F, Hawley DJ, Wilson K. The prevalence and meaning of fatigue in rheumatic disease. J Rheumatol 1996;23:1407-17.

11. Tack BB. Fatigue in rheumatoid arthritis. conditions, strategies, and consequences. Arthritis Care Res 1990;3:65-70.

12. Hewlett S, Cockshott Z, Byron M, et al. Patients' perceptions of fatigue in rheumatoid arthritis: overwhelming, uncontrollable, ignored. Arthritis Rheum 2005;53:697-702.

13. Nikolaus S, Bode C, Taal E, et al. Fatigue and factors related to fatigue in rheumatoid arthritis: a systematic review. Arthritis Care Res 2013;65:1128-46.

14. Nikolaus S, Bode C, Taal E, et al. New insights into the experience of fatigue among patients with rheumatoid arthritis: a qualitative study. Ann Rheum Dis 2010;69:895-7.

15. Mustian KM, Peppone LJ, Palesh OG, et al. Exercise and cancerrelated fatigue. US Oncol 2009;5:20-3.

16. Weijman I, Kant I, Swaen GM, et al. Diabetes, employment and fatigue-related complaints: a comparison between diabetic employees, "healthy" employees, and employees with other chronic diseases. J Occup Environ Med 2004;46:828-36.

17. Bruijning J, van Nispen R, Verstraten P, et al. A Dutch ICF version of the activity Inventory: results from focus groups with visually impaired persons and experts. Ophthalmic Epidemiol 2010;17:366-77.

18. Fritschi C, Quinn L. Fatigue in patients with diabetes: a review. J Psychosom Res 2010;69:33-41.

19. Newland P, Starkweather A, Sorenson M. Central fatigue in multiple sclerosis: a review of the literature. J Spinal Cord Med 2016;39:386-99. 
20. Asplund R, Sleep AR. Sleep, health and visual impairment in the elderly. Arch Gerontol Geriatr 2000;30:7-15.

21. Ramos AR, Wallace DM, Williams NJ, et al. Association between visual impairment and sleep duration: analysis of the 2009 National Health Interview Survey (NHIS). BMC Ophthalmol 2014;14:115.

22. van Rijn KJ, Joosse MV, Kerkhof GA. A survey of sleep disorders among Dutch visually impaired persons. Sleep-wake research in the Netherlands. Annual Proceedings of the NSWO 2014;25:72-6.

23. Flynn-Evans EE, Tabandeh H, Skene DJ, et al. Circadian rhythm disorders and melatonin production in 127 blind women with and without light perception. J Biol Rhythms 2014;29:215-24.

24. Puetz TW. Physical activity and feelings of energy and fatigue: epidemiological evidence. Sports Med 2006;36:767-80.

25. Willis JR, Jefferys JL, Vitale S, et al. Visual impairment, uncorrected refractive error, and accelerometer-defined physical activity in the United States. Arch Ophthalmol 2012;130:329-35.

26. American Psychiatric Association. Diagnostic and Statistical Manual of Mental Disorders. Fitth Edition, 2013.

27. van der Aa HP, Comijs HC, Penninx BW, et al. Major depressive and anxiety disorders in visually impaired older adults. Invest Ophthalmol Vis Sci 2015;56:849-54.

28. Repping-Wuts $\mathrm{H}$, Uitterhoeve $\mathrm{R}$, van Riel $\mathrm{P}$, et al. Fatigue as experienced by patients with rheumatoid arthritis (RA): a qualitative study. Int J Nurs Stud 2008;45:995-1002.

29. Eilertsen G, Ormstad H, Kirkevold M, et al. Similarities and differences in the experience of fatigue among people living with fibromyalgia, multiple sclerosis, ankylosing spondylitis and stroke. $J$ Clin Nurs 2015;24:2023-34.

30. Keunen JE, Verezen CA, Imhof SM, et al. Increase in the demand for eye-care services in the Netherlands 2010-2020. Ned Tijdschr Geneeskd 2011;155:A3461.

31. Leventhal H, Meyer D, Nerenz D. The common sense representation of illness danger. Rachman S, ed. Contributions to medical psychology. New York: NY: Pergamon Press, 1980:7-30.

32. Hagger MS, Orbell S. A meta-analytic review of the common-sense model of illness representations. Psychol Health 2003;18:141-84.

33. van rens G, Vreeken H, van Nispen RMA. Guideline vision disorders: Rehabilitation and referral Secondary Guideline vision disorders: Rehabilitation and referral [Internet]. 2011. http://www.reponline.nl/ uploads/hC/sf/hCsfyQHBvekdnF3fp-z2xw/Richtlijn-visusstoornissenrevalidatie-en-verwijzing.pdf.

34. Bode C, Hoek L, Köhle N. The impact of SLE-related fatigue: similar for patient and partners?.

35. Michielsen HJ, De Vries J, Van Heck GL, et al. Examination of the dimensionality of fatigue: the construction of the Fatigue Assessment Scale (FAS). European Journal of Psychological Assessment 2004;20:39-48.

36. Bruijning JE, van Rens G, Fick M, et al. Longitudinal observation, evaluation and interpretation of coping with mental (emotional) health in low vision rehabilitation using the Dutch ICF activity inventory. Health Qual Life Outcomes 2014;12:182.

37. Zuithoff NP, Vergouwe $Y$, King M, et al. The Patient Health Questionnaire-9 for detection of major depressive disorder in primary care: consequences of current thresholds in a cross-sectional study. BMC Fam Pract 2010;11:98.

38. f4transkript [program]. Marburg, 2015.

39. Pope C, Ziebland S, Mays N. Qualitative research in health care. analysing qualitative data. BMJ 2000;320:114-6.

40. Boeije HR. Analysis in Qualitative Research. London: Sage Publications Ltd, 2010.

41. Brod M, Tesler LE, Christensen TL. Qualitative research and content validity: developing best practices based on science and experience. Qual Life Res 2009;18:1263-78.

42. Hétu R, Riverin L, Lalande N, et al. Qualitative analysis of the handicap associated with occupational hearing loss. Br J Audiol 1988;22:251-64.

43. Hornsby BW. The effects of hearing aid use on listening effort and mental fatigue associated with sustained speech processing demands. Ear Hear 2013;34:523-34.

44. Barbour VL, Mead GE. Fatigue after stroke: the patient's perspective. Stroke Res Treat 2012;2012:1-6.

45. Hoffman AJ, von Eye A, Gift AG, et al. The development and testing of an instrument for perceived self-efficacy for fatigue selfmanagement. Cancer Nurs 2011;34:167-75.

46. Brunnström G, Sörensen S, Alsterstad K, et al. Quality of light and quality of life--the effect of lighting adaptation among people with low vision. Ophthalmic Physiol Opt 2004;24:274-80.

47. Huang $C Q$, Dong BR, Lu ZC, et al. Chronic diseases and risk for depression in old age: a meta-analysis of published literature. Ageing Res Rev 2010;9:131-41.

48. Rees G, Tee HW, Marella M, et al. Vision-specific distress and depressive symptoms in people with vision impairment. Invest Ophthalmol Vis Sci 2010;51:2891-6.

49. Holloway EE, Xie J, Sturrock BA, et al. Do problem-solving interventions improve psychosocial outcomes in vision impaired adults: a systematic review and meta-analysis. Patient Educ Couns 2015;98:553-64.

50. Bennett B, Goldstein D, Friedlander M, et al. The experience of cancer-related fatigue and chronic fatigue syndrome: a qualitative and comparative study. J Pain Symptom Manage 2007;34:126-35.

51. Cramp F, Byron-Daniel J. Exercise for the management of cancer-related fatigue in adults. Cochrane Database Syst Rev 2012;11:CD006145.

52. Heine M, van de Port I, Rietberg MB, et al. Exercise therapy for fatigue in multiple sclerosis. Cochrane Database Syst Rev 2015;9:CD009956.

53. Larun L, Brurberg KG, Odgaard-Jensen J, et al. Exercise therapy for chronic fatigue syndrome. Cochrane Database Syst Rev 2016;12:CD003200. 